\title{
Analisis Jaringan Syaraf Tiruan untuk Memprediksi Jumlah Narapidana pada Lembaga Pemasyarakatan Simalungun dengan Metode Backpropagation
}

\author{
Vicky Adriani ${ }^{1}$, Irfan Sudahri Damanik ${ }^{2}$, Jaya Tata Hardinata ${ }^{3}$ \\ STIKOM TUNAS BANGSA \\ Jl. Jend. Sudirman,Blok A No.1, 2, 3, Pematangsiantar \\ Vickyadriani1108@gmail.com
}

\begin{abstract}
The author has conducted research at the Simalungun District Prosecutor's Office and found the problem of prison rooms that did not match the number of prisoners which caused a lack of security and a lack of detention facilities and risked inmates to flee. Artificial Neural Network which is one of the artificial representations of the human brain that always tries to simulate the learning process of the human brain. The application uses the Backpropagation algorithm where the data entered is the number of prisoners. Then Artificial Neural Networks are formed by determining the number of units per layer. Once formed, training is carried out from the data that has been grouped. Experiments are carried out with a network architecture consisting of input units, hidden units, and output units. Testing using Matlab software. For now, the number of prisoners continues to increase. Predictions with the best accuracy use the 12-3-1 architecture with an accuracy rate of 75\% and the lowest level of accuracy using 12-4-1 architecture with an accuracy rate of 25\%.
\end{abstract}

Keywords: Prediction, Prisoners, Backpropagation, Artificial Neural Networks, Matlab

Abstrak- Penulis telah mengadakan penelitian pada Kejaksaan Negeri Simalungun dan menemukan masalah ruangan lapas yang tidak sesuai jumlah narapidanya yang menimbulkan kurangnya keamanan dan kurangnya fasilitas ruang tahanan dan beresiko narapidana melarikan diri. Jaringan Syaraf Tiruan yang merupakan salah satu representasi buatan dari otak manusia yang selalu mencoba untuk mensimulasikan proses pembelajaran otak manusia. Penerapannya menggunakan algoritma Backpropagation dimana data yang diinputkan adalah jumlah narapidana. Kemudian dibentuk Jaringan Syaraf Tiruan dengan menentukan jumlah unit setiap lapisan. Setelah terbentuk, dilakukan training dari data yang telah dikelompokkan tersebut. Percobaan dilakukan dengan arsitektur jaringan yang terdiri dari unit masukan, tersembunyi, dan unit keluaran. Pengujian dengan menggunakan software Matlab. Untuk saat ini jumlah narapidana terus meningkat. Prediksi dengan tingkat akurasi terbaik menggunakan arsitektur 12-3-1 dengan tingkat akurasi sebesar 75\% dan tingkat akurasi terendah menggunakan arsitektur 12-4-1 dengan tingkat akurasi 25\%.

Kata kunci: Prediksi, Narapidana, Backpropagation, Jaringan Syaraf Tiruan, Matlab.

\section{PENDAHULUAN}

Kecerdasan buatan (Artificial Intelegent) merupakan salah satu bagian dari ilmu komputer yang mempelajari bagaimana membuat mesin komputer dapat melakukan pekerjaan seperti dan sebaik yang dilakukan oleh manusia bahkan bisa lebih baik daripada yang dilakukan manusia [1]-[3]. Artificial Intelegent (AI) adalah untuk mengetahui dan memodelkan proses-proses berpikir manusia dan 
mendesain mesin agar dapat menirukan perilaku manusia. Cerdas, berarti memiliki pengetahuan dan pengalaman, Penalaran, bagaimana membuat keputusan dan mengambil tindakan moral yang baik.Perkembangan teknologi saat ini sangat berkembang pesat, sehingga sangat memudahkan untuk mengatasi berbagai masalah. Peranan komputer saat ini sangat membantu pekerjaan manusia sehingga lebih cepat untuk mengenali berbagai aspek, saat ini ilmu teknologi informasi juga bisa melakukan peramalan atau melakukan prediksi dengan menggunakan jaringan syaraf tiruan dengan metode Backpropagation. Backpropagation metode penurunan gradient untuk meminimilkan kuadrat error keluaran [4]-[10]. Di Kejaksaan Negeri Simalungun sering mengalami kendala yaitu bentroknya jadwal sidang jaksa, kurangnya jumlah ruang lapas dan persiapan pemberkasan perkara. Hal ini terjadi di karenakan tidak dapat diketahui secara pasti jumlah narapidana yang baru atau akan disidangkan.

\section{METODOLOGI PENELITIAN}

Dalam melakukan penelitian ini, penulis melakukan beberapa metode pengumpulan data, antara lain sebagai berikut :

a. Pengamatan langsung (Observasi)

Penulis melakukan observasi pada Kejaksaan Negeri Simalungun guna mencari data - data yang diperlukan dalam penelitian ini seperti data narapidana di Kejaksaan Negeri Simalungun.

b. Studi pustaka

Penulis mencari buku-buku, jurnal atau bahan lain yang penulis jadikan sebagai acuan dari teori-teori yang berhubungan dengan penelitian ini.

c. Data Sheet

Data yang digunakan dalam penelitian ini adalah data narapidana di Kejaksaan Negeri Simalungun mulai tahun 2016 sampai 2017

Tabel 1. Normalisasi Data

\begin{tabular}{|c|c|c|c|c|c|c|}
\hline Pola & $\mathrm{X} 1$ & $\mathrm{X} 2$ & $\ldots$. & $\mathrm{X} 11$ & $\mathrm{X} 12$ & Target \\
\hline 1 & 0.293939 & 0.766667 & $\ldots$. & 0.718182 & 0.633333 & 0.1 \\
\hline 2 & 0.766667 & 0.536364 & $\ldots$. & 0.633333 & 0.1 & 0.718182 \\
\hline 3 & 0.536364 & 0.815152 & $\ldots$. & 0.1 & 0.718182 & 0.718182 \\
\hline 4 & 0.815152 & 0.839394 & $\ldots$. & 0.718182 & 0.718182 & 0.560606 \\
\hline 5 & 0.839394 & 0.560606 & $\ldots$. & 0.718182 & 0.560606 & 0.415152 \\
\hline 6 & 0.560606 & 0.439394 & $\ldots$. & 0.560606 & 0.415152 & 0.9 \\
\hline 7 & 0.439394 & 0.584848 & $\ldots$. & 0.415152 & 0.9 & 0.342424 \\
\hline 8 & 0.584848 & 0.342424 & $\ldots$. & 0.9 & 0.342424 & 0.887879 \\
\hline 9 & 0.342424 & 0.621212 & $\ldots$. & 0.342424 & 0.887879 & 0.354545 \\
\hline 10 & 0.621212 & 0.718182 & $\ldots$. & 0.887879 & 0.354545 & 0.354545 \\
\hline 11 & 0.718182 & 0.633333 & $\ldots .$. & 0.354545 & 0.354545 & 0.487879 \\
\hline 12 & 0.633333 & 0.1 & $\ldots$. & 0.354545 & 0.487879 & 0.427273 \\
\hline
\end{tabular}

Keterangan:

$\mathrm{X} 1-\mathrm{x} 12$ :data training 
Tabel 2. Data Training

\begin{tabular}{|c|c|c|c|c|c|c|}
\hline Pola & $\mathrm{X}_{1}$ & $\mathrm{X}_{2}$ & $\ldots$. & $\mathrm{X}_{11}$ & $\mathrm{X}_{12}$ & Target \\
\hline 1 & 32 & 71 & $\ldots$. & 67 & 60 & 16 \\
\hline 2 & 71 & 52 & $\ldots$. & 60 & 16 & 67 \\
\hline 3 & 52 & 75 & $\ldots$. & 16 & 67 & 67 \\
\hline 4 & 75 & 77 & $\ldots$. & 67 & 67 & 54 \\
\hline 5 & 77 & 54 & $\ldots$. & 67 & 54 & 42 \\
\hline 6 & 54 & 44 & $\ldots$. & 54 & 42 & 82 \\
\hline 7 & 44 & 56 & $\ldots$. & 42 & 82 & 36 \\
\hline 8 & 56 & 36 & $\ldots$. & 82 & 36 & 81 \\
\hline 9 & 36 & 59 & $\ldots$. & 36 & 81 & 37 \\
\hline 10 & 59 & 67 & $\ldots$. & 81 & 37 & 37 \\
\hline 11 & 67 & 60 & $\ldots$. & 37 & 37 & 48 \\
\hline 12 & 60 & 16 & $\ldots$. & 37 & 48 & 43 \\
\hline
\end{tabular}

\subsection{Jaringan Syaraf Tiruan}

Jaringan Syaraf Tiruan (JST) (artificial neura network (ANN) / Simulated neural network (SNN) / neural network (NN) saat ini telah berkembang dengan pesat dan telah diimplementasikan dalam berbagai bidang. Jaringan syaraf tiruan merupakan salah satu aplikasi buatan manusia yang selalu mencoba untuk mensimulasikan proses pembelajaran pada otak manusia tersebut. Istilah tiruan digunakan karena jaringan saraf ini meniru cara kerja jaringan saraf biologis pada manusia dan diimplementasikan dengan menggunakan program komputer yang mampu menyelesaikan sejumlah proses perhitungan selama proses pembelajaran [11]-[24]. Backpropagation terdiri dari $n$ buah masukan (ditambah sebuah bias), sebuah layar tersembunyi yang terdiri dari $p$ unit (ditambah sebuah bias), serta $\mathrm{m}$ buah unit keluaran. $v_{o j}$ dan $w_{o k}$ masing-masing adalah bias untuk unit tersembunyi $k e-j$ dan untuk output $k e-k$. Bias $v_{o j}$ dan $w_{o k}$ berperilaku seperti bobot dimana output bias ini selalu sama dengan 1 [25]

a. Narapidana

Menurut Undang Undang Nomor 12 Tahun 1995 Tentang Pemasyarakatan, dalam Pasal 1 ayat (7) yang dimaksud Narapidana adalah terpidana yang menjalani hilang kemerdekaan di Lembaga Pemasyarakatan. Terpidana yang hilang kemerdekaan artinya, bahwa narapidana harus berada dalam Lembaga Pemasyarakatan untuk jangka waktu tertentu, sehingga negara mempunyai kesempatan untuk memperbaikinya selama di Lembaga Pemasyarakatan, Narapidana tetap memperoleh hak-haknya yang lain layaknya manusia atau warga Negara[26]Narapidana adalah seseorang yang melakukan tindak kejahatan dan telah menjalani persidangan, telah divonis hukuman pidana serta ditempatkan dalam suatu bangunan yang disebut penjara. Kata pidana identik dengan kata hukuman atau sanksi yang berat karenaberlakunya dapat dipaksakan secara langsung kepada setiap orang yang melanggar hukum. Pasal 10 KUHP (kitab undang-undang hukum pidana) mengatur macam- macam pidana sebagai berikut : 
1. Pidana pokok, terdiri dari :
a. Pidana mati
b. Pidana penjara
c. Pidana kurungan
d. Pidana denda

2. Pidana tambahan, terdiri dari :
a. Pencabutan hak hak tertentu
b. Perampasan barang barang tertentu
c. Pengumuman putusan hakim.

Perlindungan masyarakat dari tindakan yang ditimbulkan pelanggar hukum merupakan salah satu kewajiban pemerintah dalam melindungi warga negaranya untuk tetap menciptakan rasa aman. Pemerintah menyediakan suatu lembaga untuk memutus dan berwenang menghilangkan kemerdekaan si pelanggar hukum. Mereka yang diputus oleh putusan hakim dengan pidana penjara atau pidana kurungan dinamakan narapidana.

b. Prediksi

Peramalan atau prediksi adalah memperkirakan besar atau jumlah sesuatu pada waktu yang akan datang berdasarkan data pada masa lampau yang dianalisis secara ilmiah khususnya menggunakan metode statistika. Prediksi muncul di banyak masalah dunia nyata, misalnya, pasar keuangan, pemrosesan sinyal, peramalan cuaca dan lain-lain [1].

c. Kerangka Kerja Penelitian

Kerangka kerja penelitian yang digunakan dalam menyelesaikan masalah penelitian ini.

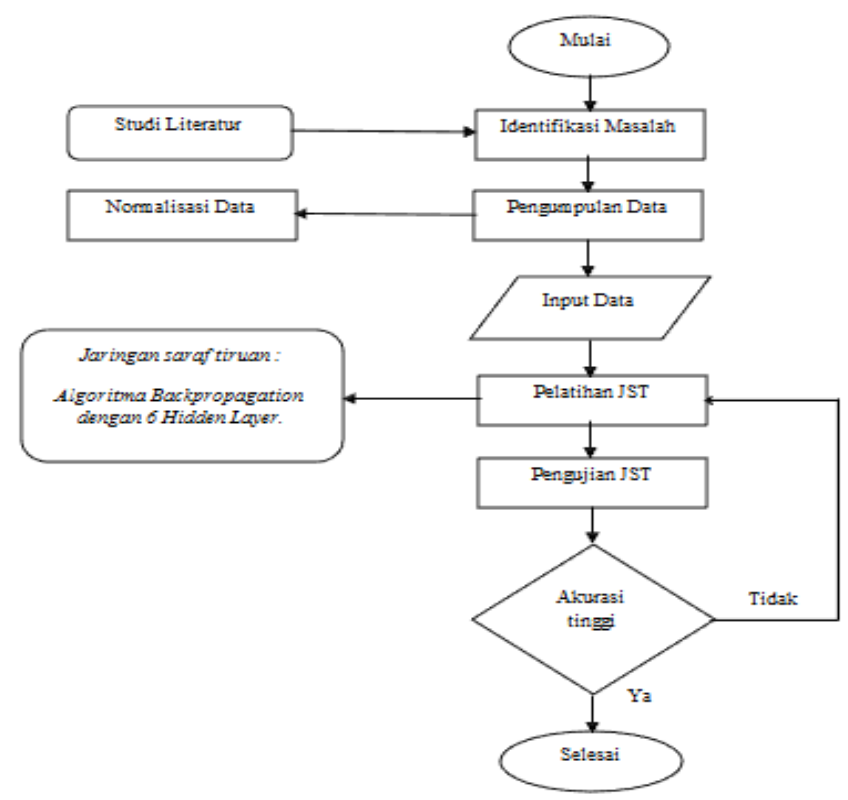

Gambar 1. Kerangka Kerja Penelitian

Berdasarkan kerangka kerja penelitian pada gambar 1 diatas maka masingmasing langkah dapat diuraikan sebagai berikut : 
a. Mengidentifikasi Masalah

Pada tahap identifikasi masalah ini, dilakukan setelah semua data-data terpenuhi kemudian didapatkan dataset yang sesuai untuk dilakukan proses pada tahap konversi data yang didapat sesuai dengan bobot yang ditentukan.

b. Studi Pustaka

Pada tahap ini, data-data yang diperoleh berasal dari Kejaksaan Negeri Simalungun dengan menggunakan beberapa metode penelitian.

c. Pengumpulan Data

Pengumpulan data dilakukan dengan tujuan memilih data mana yang sesuai dengan permasalahan dan dapat digunakan sebagai atribut untuk dibaca pada algoritma backpropagation.

d. Normalisasi Data

Data yang diperoleh akan melalui tahap normalisasi menjadi bilangan bilangan atau angka yang dapat diproses pada algoritma backpropagation maupun dengan aplikasi matlab yang akan digunakan pada saat pelatihan maupun pengujian.

e. Input Data

Data yang telah melewati proses normalisasi dapat diinput kedalam perhitungan dan program untuk selanjutnya diproses ke tahap pelatihan.

f. Pelatihan JST

Data yang diinput merupakan data training tahun 2016 dimasukkan kedalam perhitungan backpropagation beserta dengan bobot biasnya melalui hidden layer untuk memperoleh output dengan meminimalisir error.

\subsection{Arsitektur Jaringan}

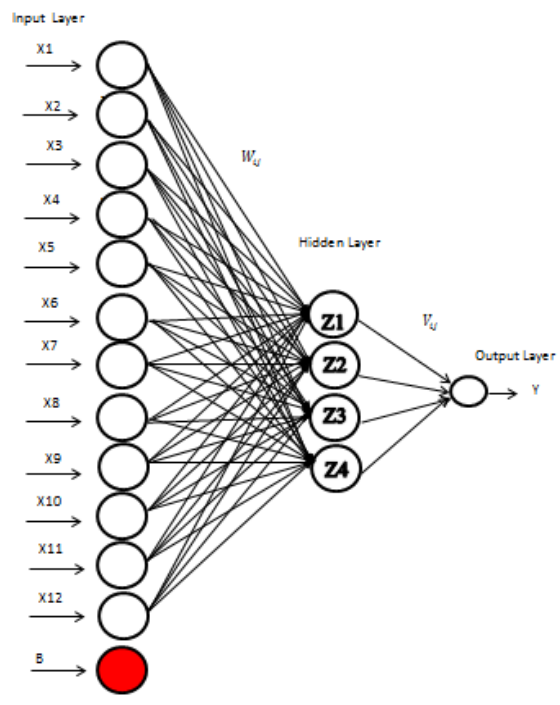

Gambar 2. Arsitektur Backpropagation Prediksi Narapidana

Keterangan :

$\begin{array}{ll}\mathrm{X}_{1}-\mathrm{X}_{12} & : \text { Data masukan (input layer) } \\ \mathrm{b} & : \text { Bias }\end{array}$

Analisis Jaringan Syaraf Tiruan Untuk Memprediksi Jumlah Narapidana(Vicky Adriani)|766 


$\begin{array}{ll}\mathrm{V}_{\mathrm{ij}} & \text { : Bobot ke simpul hidden } \\ \mathrm{W}_{\mathrm{ij}} & \text { : Bobot ke simpul output } \\ \mathrm{Z}_{1}-\mathrm{Z}_{\mathrm{n}} & \text { : Hidden layer } \\ \mathrm{Y} & \text { : Hasil keluaran (output) }\end{array}$

\section{HASIL DAN PEMBAHASAN}

\subsection{Analisis}

Sebelum Training dilakukan, terlebih dahulu ditentukan nilai parameter yang diinginkan guna memperoleh hasil yang optimal. Parameter-parameter yang digunakan secara umum pada aplikasi Matlab untuk training dan testing dapat dilihat pada kode berikut :

> clear;

$>>$ close all;

$>>$ warning off;

> \% Proses input data training, data pelatihan dan data target pelatihan

$>$ filename = 'Data2019.xlsx';

$>$ sheet $=1$;

$>$ xlRange = 'Q4:AC15';

$>$ Data_Pelatihan = Data_Training(:,1:12)';

$>>$ Target_Pelatihan = Data_Training(:,13)';

$>>[\mathrm{m}, \mathrm{n}]=$ size(Data_Training);

$>$ \%Proses input data test, data Uji dan data target uji

$>$ filename = 'Data2020.xlsx';

$>$ sheet $=1$;

$>$ xlRange1 = 'Q33:AC33';

>> Data_Test = xlsread(filename, sheet, $x l$ Range1);

$>$ > Data_Uji = Data_Test(:,1:12)';

$>>$ Target_Uji = Data_Test(:,13)';

> \% Proses Pembuatan Jaringan JST BP Dengan POLA I = $12, \mathrm{HL}=10$ dan Output

= 1 serta Fugsi Aktifasi "'tansig','logsig'" dan TrainF = 'traingdx'

>> net=newff(minmax(Data_Pelatihan),[3,1],\{'purelin','logsig'\},'traingd');

$>$ \%Proses Pembuatan Bias 1

$>$ net.b $\{1\}$;

>> \%Proses Pelihatan Bobot Awal Pada Lapisan Tersembunyi 1 dan 2

$>$ net.LW $\{2,1\}$;

$>>$ \% Proses Pembuatan Bias 2

$>$ net.b $\{2\}$;

>> \%Proses Penentuan Parameter JST

$>>$ net.trainParam.epochs $=10000$;

$>>$ net.trainParam.show $=1000$;

$>>$ net.trainParam. $\operatorname{Lr}=0.04$;

$>>$ net.trainParam.goal $=0.03$;

>> \%Proses Pembentukan Jaringan JST "net"

$>$ net=train(net,Data_Pelatihan,Target_Pelatihan);

> \% Proses Pengujian Jaringan JST "net" Terhadap Target Pelatihan (DATA

TRAINING) HPT = HASIL PREDIKSI TARGET, EPT = ERROR PREDIKSI TARGET dll 
$>>$ [HPT,Pf,Af,EPT,Perf]=sim(net,Data_Pelatihan,[],[],Target_Pelatihan);

$>$ \%Proses Pengujian Jaringan JST "net" Terhadap Target Pelatihan (DATA TEST)

HPU = HASIL PREDIKSI UJI, EPU = ERROR PREDIKSI UJI dll

>> [HPU,Pf,Af,EPU,Perf]=sim(net,Data_Uji,[],[],Target_Uji);

\subsection{Hasil}

Penelitian ini menggunakan 3 pola. Antara lain 12-3-1, 12-4-1, 12-6-1, dari ke 3 arsitektur ini, pola terbaik yaitu 12-3-1 dengan tingkat akurasi sebesar 75\%.

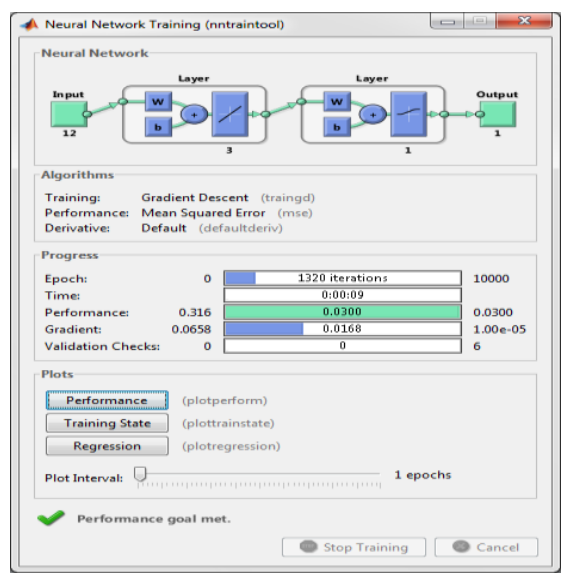

Gambar 3. Hasil Pelatihan pola 12-3-1

Dari gambar model arsitektur 12-3-1 diatas dapat dijelaskan bahwa Epoch yang terjadi sebesar 1320 dengan lama waktu 9 detik.

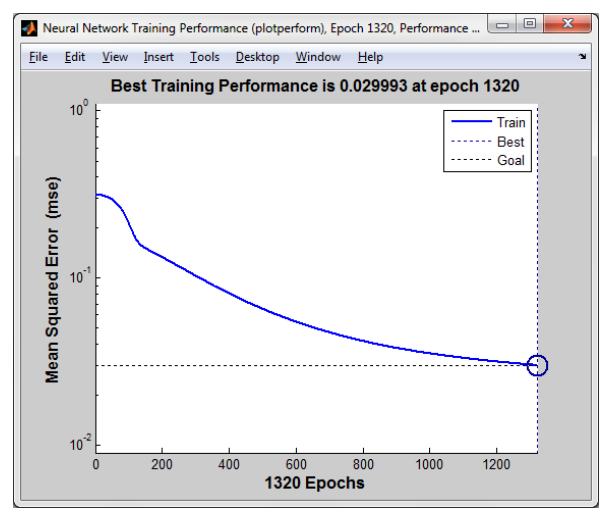

Gambar 4. Grafik performance 12-3-1

Dari gambar model arsitektur 12-3-1 dijelaskan bahwa dari Epoch training dapat diperoleh Mean Square Error (MSE) sebesar 0.029993.

\section{KESIMPULAN}

Kesimpulan yang dapat diambil setelah melakukan pelatihan dan pengujian data pada jaringan syaraf tiruan dengan menggunakan algoritma backpropagation adalah sebagai berikut : 
a. Pemodelan backpropagation dibagi menjadi 2 yaitu model pelatihan dan model pengujian. Model pelatihan dilakukan dengan menggunakan jumlah variabel input yaitu tahun 2016 sampai dengan target tahun 2017, hidden layer dan output. Model pengujian dilakukan dengan menggunakan jumlah variabel input yaitu tahun 2017 sampai dengan target tahun 2018.

b. Pemodelan terbaik pada penelitian ini adalah 12-3-1 dengan menggunakan learning rate 0.04 , nilai toleransi minimum pada penelitian ini adalah 0.001 dan mendapatkan tingkat akurasi sebesar 75 \%. Dengan pola 12-3-1 tersebut selanjutnya dilakukan prediksi untuk tahun 2019 sampai dengan 2020. Dengan ini metode backpropagation relevan dalam memprediksi jumlah narapidana di lembaga pemasyarakatn simalungun.

c. Hasil prediksi yang dihasilkan dari jaringan syaraf tiruan ini dapat membantu pihak kejaksaan dalam menentukan jadwal sidang jaksa dalam proses sidang di pengadilan.

\section{DAFTAR PUSTAKA}

[1] A. Wanto and A. P. Windarto, "Analisis Prediksi Indeks Harga Konsumen Berdasarkan Kelompok Kesehatan Dengan Menggunakan Metode Backpropagation," Jurnal \& Penelitian Teknik Informatika Sinkron, vol. 2, no. 2, pp. 37-44, 2017.

[2] A. Wanto, A. P. Windarto, D. Hartama, and I. Parlina, "Use of Binary Sigmoid Function And Linear Identity In Artificial Neural Networks For Forecasting Population Density," International Journal of Information System \& Technology, vol. 1, no. 1, pp. 43-54, 2017.

[3] A. Wanto, M. Zarlis, Sawaluddin, and D. Hartama, "Analysis of Artificial Neural Network Backpropagation Using Conjugate Gradient Fletcher Reeves in the Predicting Process," Journal of Physics: Conference Series, vol. 930, no. 1, pp. 1-7, 2017.

[4] S. P. Siregar and A. Wanto, "Analysis of Artificial Neural Network Accuracy Using Backpropagation Algorithm In Predicting Process (Forecasting)," International Journal of Information System \& Technology, vol. 1, no. 1, pp. 34-42, 2017.

[5] J. R. Saragih, M. Billy, S. Saragih, and A. Wanto, "Analisis Algoritma Backpropagation Dalam Prediksi Nilai Ekspor (Juta USD)," Jurnal Pendidikan Teknologi dan Kejuruan, vol. 15, no. 2, pp. 254-264, 2018.

[6] E. Hartato, D. Sitorus, and A. Wanto, "Analisis Jaringan Saraf Tiruan Untuk Prediksi Luas Panen Biofarmaka di Indonesia," Jurnal semanTIK, vol. 4, no. 1, pp. 49-56, 2018.

[7] S. Setti and A. Wanto, "Analysis of Backpropagation Algorithm in Predicting the Most Number of Internet Users in the World," JOIN (Jurnal Online Informatika), vol. 3, no. 2, pp. 110-115, 2018.

[8] R. E. Pranata, S. P. Sinaga, and A. Wanto, "Estimasi Wisatawan Mancanegara Yang Datang ke Sumatera Utara Menggunakan Jaringan Saraf," Jurnal semanTIK, vol. 4, no. 1, pp. 97-102, 2018.

[9] A. A. Fardhani, D. Insani, N. Simanjuntak, and A. Wanto, "Prediksi Harga Eceran Beras Di Pasar Tradisional Di 33 Kota Di Indonesia Menggunakan Algoritma Backpropagation," Jurnal Infomedia, vol. 3, no. 1, pp. 25-30, 2018.

[10] J. Wahyuni, Y. W. Paranthy, and A. Wanto, "Analisis Jaringan Saraf Dalam Estimasi Tingkat Pengangguran Terbuka Penduduk Sumatera Utara," Jurnal Infomedia, vol. 3, no. 1, pp. 1824, 2018.

[11] A. Wanto et al., "Levenberg-Marquardt Algorithm Combined with Bipolar Sigmoid Function to Measure Open Unemployment Rate in Indonesia," in Conference Paper, 2018, pp. 1-7.

[12] I. A. R. Simbolon, F. Yatussa'ada, and A. Wanto, "Penerapan Algoritma Backpropagation dalam Memprediksi Persentase Penduduk Buta Huruf di Indonesia," Jurnal Informatika Upgris, vol. 4, no. 2, pp. 163-169, 2018.

[13] S. P. Siregar, A. Wanto, and Z. M. Nasution, "Analisis Akurasi Arsitektur JST Berdasarkan Jumlah Penduduk Pada Kabupaten / Kota di Sumatera Utara," in Seminar Nasional Sains \& 
Teknologi Informasi (SENSASI), 2018, pp. 526-536.

[14] A. Wanto, "Optimasi Prediksi Dengan Algoritma Backpropagation Dan Conjugate Gradient Beale-Powell Restarts," Jurnal Teknologi dan Sistem Informasi, vol. 3, no. 3, pp. 370-380, Jan. 2018.

[15] B. K. Sihotang and A. Wanto, "Analisis Jaringan Syaraf Tiruan Dalam Memprediksi Jumlah Tamu Pada Hotel Non Bintang," Jurnal Teknologi Informasi Techno, vol. 17, no. 4, pp. 333346, 2018.

[16] M. A. P. Hutabarat, M. Julham, and A. Wanto, "Penerapan Algoritma Backpropagation Dalam Memprediksi Produksi Tanaman Padi Sawah Menurut Kabupaten/Kota di Sumatera Utara," Jurnal semanTIK, vol. 4, no. 1, pp. 77-86, 2018.

[17] Y. Andriani, H. Silitonga, and A. Wanto, "Analisis Jaringan Syaraf Tiruan untuk prediksi volume ekspor dan impor migas di Indonesia," Register - Jurnal Ilmiah Teknologi Sistem Informasi, vol. 4, no. 1, pp. 30-40, 2018.

[18] A. Wanto, "Penerapan Jaringan Saraf Tiruan Dalam Memprediksi Jumlah Kemiskinan Pada Kabupaten/Kota Di Provinsi Riau," Kumpulan jurnaL Ilmu Komputer (KLIK), vol. 5, no. 1, pp. 61-74, 2018.

[19] I. S. Purba and A. Wanto, "Prediksi Jumlah Nilai Impor Sumatera Utara Menurut Negara Asal Menggunakan Algoritma Backpropagation," Jurnal Teknologi Informasi Techno, vol. 17, no. 3, pp. 302-311, 2018.

[20] A. Wanto, "Prediksi Angka Partisipasi Sekolah dengan Fungsi Pelatihan Gradient Descent With Momentum \& Adaptive LR," Jurnal Ilmu Komputer dan Informatika (ALGORITMA), vol. 3, no. 1, pp. 9-20, 2019.

[21] N. Nasution, A. Zamsuri, L. Lisnawita, and A. Wanto, "Polak-Ribiere updates analysis with binary and linear function in determining coffee exports in Indonesia," IOP Conference Series: Materials Science and Engineering, vol. 420, no. 12089, pp. 1-9, 2018.

[22] A. Wanto, "Prediksi Produktivitas Jagung Indonesia Tahun 2019-2020 Sebagai Upaya Antisipasi Impor Menggunakan Jaringan Saraf Tiruan Backpropagation," SINTECH (Science and Information Technology), vol. 1, no. 1, pp. 53-62, 2019.

[23] B. Febriadi, Z. Zamzami, Y. Yunefri, and A. Wanto, "Bipolar function in backpropagation algorithm in predicting Indonesia's coal exports by major destination countries," IOP Conference Series: Materials Science and Engineering, vol. 420, no. 12089, pp. 1-9, 2018.

[24] A. Wanto et al., "Analysis of Standard Gradient Descent with GD Momentum And Adaptive LR for SPR Prediction," 2018, pp. 1-9.

[25] M. R. Lubis, "Analisis Jaringan Saraf Tiruan Back Propgation Untuk Peningkatan Akurasi Prediksi Hasil Pertandingan Sepakbola," TECHSI, vol. 10, pp. 50-62, 2018.

[26] Petrus Irwan Panjaitan and P. Simorangkir, "IMPLEMENTASI HAK HAK NARAPIDANA UNTUK MENDAPATKAN UPAH / PREMI ATAS PEKERJAAN YANG DILAKUKAN DI LEMBAGA PEMASYARAKATAN PAJANGAN KELAS 11 B BANTUL," 2013. 